\title{
Factores que aumentan la incidencia de inundaciones por Precipitaciones Pluviales en núcleos urbanos de la Ciudad Capital, Panamá. Caso de estudio en la Ave. Domingo Diaz.
}

\section{Factors that increase the incidence of flooding due to rainfall in urban areas of the Capital City, Panama. Case study in Ave. Domingo Diaz Ave.}

\author{
Isaac Ernesto Trejos Saucedo ${ }^{1}$, Gilda Achurra ${ }^{2}$. \\ ${ }^{1}$ Escuela de Ingeniería Civil. Facultad de Ingeniería y Tecnología. Universidad Santa María la Antigua \\ (Panamá). \\ https://orcid.org/0000-0002-8486-576X \\ ${ }^{2}$ Escuela de Ingeniería Civil. Facultad de Ingeniería y Tecnología. Universidad Santa María la Antigua \\ (Panamá). \\ https://orcid.org/0000-0003-0148-1056
}

*Autor por correspondencia: Isaac Ernesto Trejos Saucedo, isaac.trejos02@gmail.com

Recibido: 05 de abril de 2021

Aceptado: 15 de julio de 2021

\section{Resumen}

Este trabajo analiza la situación de 7 kilómetros de la avenida Domingo Diaz a través de 7 núcleos de inundacion, evaluados en los años 2016 y 2019 posterior a la construcción de obras civiles muy importantes como: la ampliación a cuatro carriles de la avenida Domingo Diaz y la construcción de la Línea 2 del Metro de Panamá, empleando revisiones fotográficas para detectar cambios en el comportamiento de estos núcleos de inundacion, después de la construcción de cada obra en sus respectivos años de culminación. Se evalúa, a partir del comportamiento en cada núcleo de inundacion, factores que inciden en sus réplicas de inundacion a través de los años, como el crecimiento urbano en la parte alta de las cuencas urbanas que discurren sobre la avenida Domingo Diaz, en sus 7 kilómetros analizados, el aumento de áreas impermeables, aumento del nivel del mar con respecto a la ciudad de Panamá y el creciente impacto por cambio climático al que está expuesta toda ciudad. La amplia revisión bibliográfica, actual y pionera en su momento, de los factores que se estudian en el documento, muestran falencia existente en el área de análisis, así como dan a conocer múltiples informaciones y reiteran lecciones aprendidas en otras latitudes, impactadas por estos mismos factores en ciudades costeras como la ciudad de Panamá.

El análisis muestra que todos los núcleos inundables evaluados en 2016, con réplicas de inundacion posterior a la ampliación a cuatro carriles de la avenida Domingo Diaz, mantienen su recurrencia de inundacion en 2019, posterior a la construcción de la Línea 2 del Metro de Panama, a pesar de contar obras que "renovarían del sistema pluvial" siguen utilizando exclusivamente soluciones rígidas grises insuficientes para resolver el problema de inundacion. Estas soluciones rígidas, ascienden con gastos de 273 millones de dólares, por la ampliación a cuatro carriles de la avenida en 2016 y de 1,875 millones, por la construcción de la Línea 2 del Metro de Panamá. Además, hasta la fecha el Ministerio de Obras Públicas (MOP) no incluye en sus Términos de Referencia, para aprobación de planos para drenaje pluvial, ninguna consideración debida a variaciones en el patrón de lluvias en los análisis hidrológicos (Centroamericana, 2016), ni una integración entre el drenaje de agua de lluvia, la inundación de agua de mar y la protección de la costa, ni de planificación 
urbana, ni pruebas de que el plan que sostiene de continuar con construcciones de obras estructurales rígidas más grandes, sea la mejor solución para mitigar los problemas de inundación en el núcleo de análisis.

Palabras clave: Domingo Diaz; Drenaje Pluvial; Crecimiento Urbano; Aumento del Nivel del Mar; Cambio Climático.

\begin{abstract}
This work analyzes the situation of 7 kilometers of Domingo Diaz Avenue through 7 flood centers, evaluated in 2016 and 2019 after the construction of essential civil works such as the extension to four lanes of Domingo Diaz Avenue and the construction of Line 2 of the Panama Metro, using photographic reviews to detect changes in the behavior of these flood centers, after the construction of each work in their respective years of completion. Factors affecting its flood replicas over the years include urban growth at the top of the urban basins running on Domingo Diaz Avenue. Its 7 kilometers analyzed, the increase in impervious areas, rising sea levels relative to Panama City, and the growing climate change impact to which every city is exposed are assessed from behavior in each flood core. The extensive bibliographic review, current and pioneering at the time, of the factors, studied in the document, show lack existing in the area of analysis, as well as publicize multiple information and reiterate lessons learned in other latitudes, impacted by these same factors in coastal cities such as Panama City. Analysis shows that all flood-flood cores evaluated in 2016, with post-extension flood replicas of four lanes of Domingo Diaz. Avenue, maintain their flood recurrence in 2019, following the construction of Panama Metro Line 2, despite counting works that would "renew the storm system" continue to exclusively use insufficient grey rigid solutions to solve the flood problem. These rigid solutions amount to expenses of $\$ 273$ million, for the extension to four lanes of the avenue in 2016 and 1,875 million, for Line 2 of the Panama Metro. In addition, to date, the Ministry of Public Works (MOP) does not include in its Terms of Reference, for approval of plans for storm drainage, any consideration due to variations in the pattern of rainfall in hydrological analyses (Central American, 2016). Nor an integration between rainwater drainage, seawater flooding, and coastal protection, neither urban planning nor evidence that the plan contends to continue with more significant rigid structural constructions is the best solution to mitigate flooding problems in the analysis core.
\end{abstract}

Keywords: Domingo Díaz avenue; storm drain; urban growth; Rising sea levels; climate change.

\title{
Introducción
}

Las carreteras son una fuente de progreso y bienestar para campos, pueblos y ciudades. Su buen estado y mantenimiento garantizan la sostenible circulación de vehículos y medios de transportes públicos y privados, así como el movimiento de cargas, pilar fundamental de ingresos en parte de la economía de la ciudad de Panamá.

El alma de las carreteras es el buen drenaje superficial (SIECA, Manual Centroamericano de Normas para el Diseño Geométrico de Carreteras, 2011), hoy por hoy, el agua sigue siendo el primer factor que disminuye la calidad de funcionamiento en una vía. Por esto, la capacidad de alejar las aguas lo más rápido posible de las carreteras en zonas urbanas sigue siendo un reto de la ingeniería moderna.

Ninguna característica en una carretera tiene mayor influencia sobre la seguridad y confort de la conducción que el ancho y la condición de la superficie (Officials, 2011).

El objetivo del diseño del drenaje pluvial de la carretera es proporcionar un paso seguro de vehículos durante el evento de tormenta de diseño. A medida que aumenta la propagación desde la acera, aumentan los riesgos de accidentes de tráfico y retrasos, así como las molestias y posibles peligros para el tráfico de peatones (Administration, 2009).

Según el Banco Interamericano de Desarrollo se estima que en el 2040 el 70\% de la población mundial vivirá en zonas urbanas (ONU, 2019). Y nuestra ciudad no escapa de este crecimiento, en las últimas tres decenas de años, la ciudad ha experimentado un alto crecimiento demográfico, duplicando su población de 830 mil habitantes en 1990, a 1.4 millones en 2017 (Rockefeller, 2017). Este crecimiento, determinado en gran parte por la migración campo-ciudad aunado a los problemas socio-políticos de muchos vecinos en América Latina y el Caribe ha resultado por triplicar la huella urbana, al pasar de 12 mil hectáreas en 1990 a más de 33 mil y creciendo en la actualidad. Hoy la huella urbana de la ciudad, supera los 80 kilómetros de Este a Oeste (BID, 2015).

Los gestores de la carretera de todo el mundo se enfrentan a fenómenos climáticos, aumento de áreas urbanas y catástrofes 
naturales cada vez más frecuentes y graves. En los últimos 20 años, las pérdidas económicas notificadas debido a fenómenos meteorológicos extremos han aumentado un $151 \%$ en comparación con el período 1978-1998, alcanzando los 2.250 millones de dólares estadounidenses (UNISDR, 2017).

Según el Plan Nacional de Seguridad Hídrica 2015-2050, en los últimos 5 años, el Estado Panameño ha invertido cerca de US\$ 331.03 millones en reconstrucciones de asentamientos por eventos climatológicos extremos, todos relacionados con el agua (Panamá C. N., 2015).

En la última década, a nivel nacional, se ha registrado un incremento del número de personas afectadas anualmente por desastres naturales, pasando de 4,623 en el 2001 a 19,950 en el 2011, siendo los años con el mayor número de afectados el 2008 y 2010, con más de 65 mil personas afectadas durante cada uno de esos años (Desastres, 2019).

El Sistema Nacional de Protección Civil (SINAPROC) no cuenta con información pública sobre el costo anual que generan las inundaciones en el núcleo urbano de análisis, ni en el resto de la ciudad de Panamá, en movilización de rescatista, equipo, contención de daños, reorganización de familias damnificadas y la reconstrucción de propiedad privada y pública. Los datos almacenados en la base de datos de DESINVENTAR dan una idea sobre esta información. Según la base de datos las inundaciones de 2008 alcanzaron costos por 15,000,000 millones de dólares, en 2010 (con la Purísima) cerca de 149,000,000 millones, en 2013 500,000 mil dólares y en 2018 cerca de 128,000 mil dólares (Desastres, 2019). Estos datos son solo los registrados en la plataforma, por lo que podrían ser valores superiores a estos números. Es de esperarse que la inundación terrestre, es el evento de riesgo más costoso que resguarda el Sistema Nacional de Protección Civil.

\section{Propuesta}

El objetivo de este estudio es comprender los factores que inciden en las inundaciones en 7 kilómetros del núcleo urbano ubicado en la avenida Domingo Diaz, desde las proximidades del cruce de la Domingo Diaz con el rio Matías Hernandez hasta pasado el cruce del rio Juan Diaz con la misma avenida. Se evaluarán, específicamente, 7 nodos de inundación comparando su comportamiento en los años 2016 y 2019 posterior a la rehabilitación del sistema de drenaje pluvial existente posterior a la construcción de obras civiles importantes.

La decisión sobre el núcleo de estudio fue con base en una observación continua del estado de la avenida Domingo Diaz en el periodo 2016 y 2019 y su comportamiento en época lluviosa.

La observación permitió encontrar un comportamiento repetitivo, al de 2016, sobre la Domingo Diaz en el periodo en 2019, las zonas inundables, dentro del núcleo de análisis, eran las mismas en ambos periodos de tiempo. De todas las zonas inundables tres presentaban el mayor grado de vulnerabilidad, todas en áreas cercanas a los cruces de cauces a lo largo de la vía. Dentro de los 7 kilómetros del área de análisis se encuentran los ríos Matías Hernández, Palomo y Juan Diaz que fueron observados como el área más vulnerable de la avenida Domingo Diaz.

La planificación de esta investigación se centra en responder tres preguntas principales. Las preguntas 1 y 2 son tratadas en la fase de análisis del proyecto y la pregunta 3 es la etapa de evaluaciones.

Pregunta 1. ¿Cuáles son los factores de incidencia, de las inundaciones en el área de estudio?

Pregunta 2. ¿Los planes actuales de las instituciones públicas funcionarán para resolver el problema o siguen el mismo camino de años anteriores?

Pregunta 3. ¿Cuál es la posibilidad del área de análisis para aumentar su resiliencia y minimizar las inundaciones?

\section{Una mirada al pasado en busca de respuestas}

Una definición poética sobre las carreteras la escribió el ingeniero panameño Elías Allain en 1977: "El desarrollo vial de un país siempre ha representado un factor muy importante, para planificador, urbanista, gobernador, etcétera. Puesto que una vía tiene implicaciones profundas en la vida de una región. Su radio de acción es enorme y sus efectos repercuten en la economía, cultura, e incluso en la estructura física social de los hombres".

El primer paso de la nueva república en pro del desarrollo del país data del 23 de febrero de 1904, cuando mediante el decreto No. 3, se creó la Secretaría de Obras Públicas, que cumplía el objetivo de satisfacer la necesidad de contar con una institución responsable de la construcción y el mantenimiento de las diferentes obras del Estado en el primer período republicano de 
nuestro país. Pero no fue hasta 1920 cuando se crea la Junta Central de Camino (1920 a 1936) (Chong, 1998), creada con el objetivo de proveer al país de vías terrestres de comunicación que facilitarán primordialmente las relaciones económicas y la fácil injerencia del Estado sobre el resto del país.

En el libro Panamá Cosmopolita: La Exposición de 1916 y su legado, se describe: "La modernidad llego de golpe a Panamá a raíz del descubrimiento de oro en California en 1848, aun hubo que esperar 20 años para que sus calles y plazas adquiriesen una apariencia más cosmopolita".

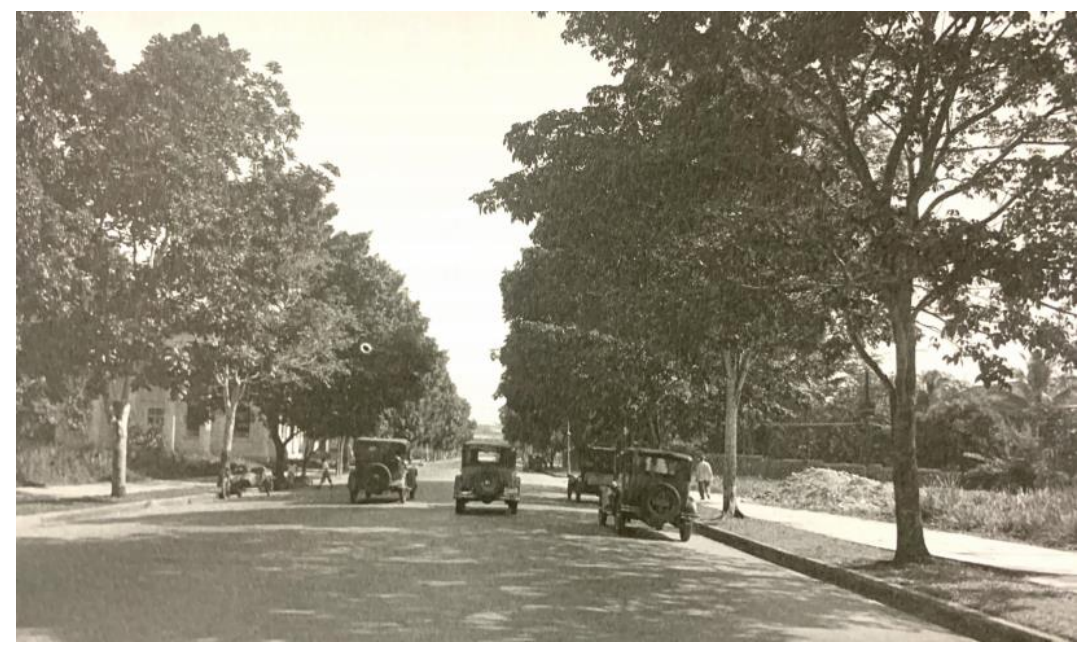

Ilustración 1. Una avenida del Barrio de la Exposición en 1930. (500, 2017)

De ahí para las próximas décadas se inicia la construcción de estructuras que recojan el agua que escurre de la superficie del camino debido al bombeo, así como también la que escurre desde sus taludes a los extremos de la vía, estas estructuras llamadas "cunetas", iban de acuerdo con la cantidad de agua que debía escurrir ajustado también a la amplitud de rodadura o ancho del camino.

A finales de la década de los años 60, ya se había prescindido de las cunetas rectangulares por su baja capacidad de movilizar basura y elementos naturales que caían en ella, empozando y manteniendo cantidades de agua suficientes para producir mosquitos, malos olores y bajos rendimientos de escurrimiento.

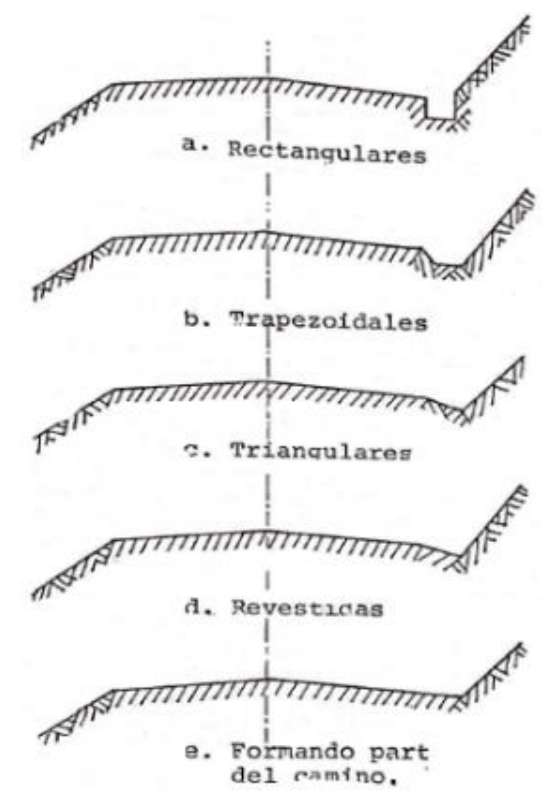

Ilustración 2. Tipos de Cunetas utilizadas para la de carga de aguas pluviales. (Tello, 1977) 
Isaac Ernesto Trejos - Saucedo, et al. DOI: https://doi.org/10.37387/ipc.v9i3.261

\section{Análisis de factores que inciden en la recurrencia de inundaciones por precipitaciones pluviales en el área de estudio}

Para obtener una comprensión más profunda de la naturaleza del problema, el problema se dividirá en partes manejables. Se analizarán exclusivamente la hipótesis de la incidencia de estos factores y su incidencia en las inundaciones por lluvia como: Crecimiento urbano en la parte alta de las cuencas y aguas abajo de las mismas y su impacto en la escorrentía superficial; Aumento en el nivel del mar; Cambio Climático, modificación en los patrones de lluvia sobre el área de análisis; Estado del sistema de drenaje existente.

\section{Crecimiento urbano en la parte alta de las cuencas y aguas abajo de las mismas}

Según el profesor Ángel Rubio "el despertar por la preocupación del ordenamiento territorial de la ciudad comienza en 1940 con el Informe y Plan Regulador presentado por Kart Brunner y sigue después con la creación del Banco de Urbanización y Rehabilitación en 1944" (Gordon, 2019). Ya en 1977 se planteaba un gran número de conexiones, tanto longitudinales como transversales, esto para garantizar la conectividad entre las troncales de la ciudad y dirigir con esto hacia donde ubicar el crecimiento urbano.

El Metro de Panamá se ha convertido en ese "regulador urbano" de la ciudad con la construcción de las Líneas 1 y 2 del Metro de Panamá transformando a partir de estas nuevas líneas avenidas existentes en arterias suburbanas como parte del plan de integral del metro, un plan que no cuenta con todas las medidas de mitigación a posibles problemas causados en su proceso "urbano".

(Uribe A., 2020) cuenta que "La arteria metropolitana por la que transcurrirá el metro tiene actualmente un carácter suburbano que se modificará con la aparición de las estaciones de metro. Entorno a éstas se deberán planificar áreas de centralidad, que dotarán al eje de una sucesión de subcentros de actividad entorno a las estaciones. Igualmente, los espacios entre las estaciones serán referencias de centralidad para las zonas aledañas, por lo que la Avenida Domingo Díaz deberá en realidad transformarse de arteria suburbana, prolongación de una carretera interestatal, en un corredor de centralidad urbana vertebrador de la ciudad. Para cumplir con este objetivo es necesario identificar las actuaciones que permitirán aprovechar las oportunidades que abre la nueva infraestructura, y multiplicar sus impactos positivos.

Las actuaciones en su conjunto se alinean con una visión estratégica general que dirige la transformación de esta parte de la ciudad y que en este caso se condensa en un gran objetivo transformador: la reconversión de la Avda. Domingo Díaz en un eje urbano vertebrador de la ciudad, basado en la presencia del transporte masivo."

Aguas arriba de los ríos Matías Hernández, Palomo y Juan Diaz el crecimiento urbano sigue aumentando con los años. Gracias a las imágenes satelitales se logra ver los cambios en el uso de suelo aguas arriba.

Desde 2002 la huella urbana aguas arriba de las cuencas, han experimentado un crecimiento continuo, contando en 2002 con 1,883 hectáreas hasta hoy en 2020 contar con 1,341 hectáreas con una pérdida del 28,78\% de la cobertura vegetal. En las imágenes también se muestra las ubicaciones de desarrollos urbanos aislados dentro de la zona verde, marcados en color morado (ver ilustración 3), que en 2002 no representaban poco menos de 4 hectáreas para contar hoy con 68 hectáreas cubiertas dentro de la zona vegetal existente. Si restamos esa área de 68 hectáreas a la zona total existe pasaríamos de 1,341 hectáreas a solo 1,273 hectáreas de área verde aguas arriba de los ríos.

Hoy, no existen un límite urbano ni zonas de expansión planificadas, pues no existe una estrategia metropolitana de crecimiento, experimentándose un crecimiento de la huella urbana aleatorio y desorganizado. Esto a pesar de los esfuerzos por parte del Municipio de Panamá y la sociedad civil de crear y aprobar el POT (Plan de Ordenamiento Territorial) a la fecha no se logrado un acuerdo para aprobarlo. 


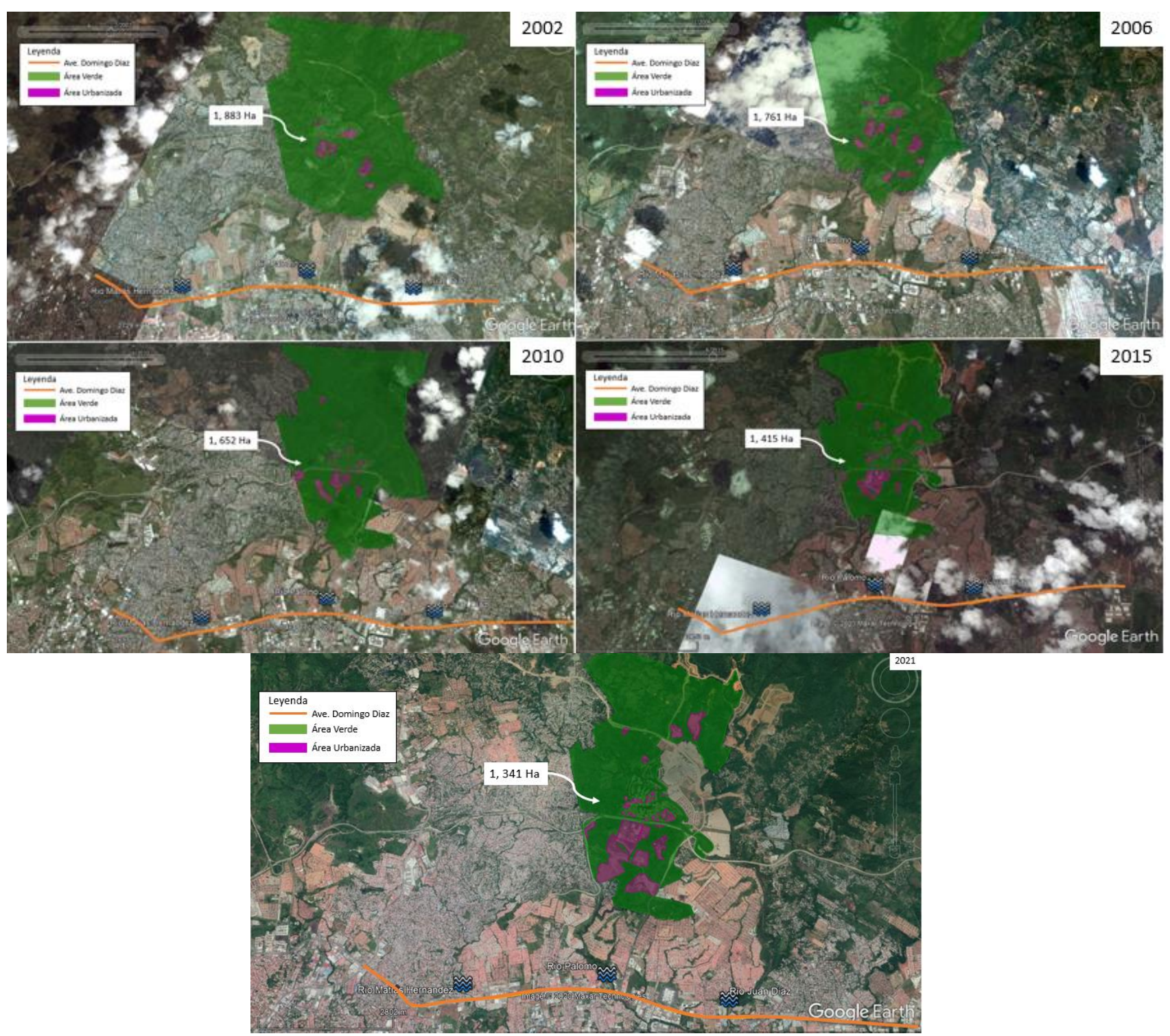

Ilustración 3. Crecimiento urbano aguas arriba de las cuencas analizadas dentro del área de análisis. Elaboración propia

Además, aumentan las viviendas ubicadas en suelos con pendientes superiores al 30\% (MUPA B. , 2017). Hoy el 8,38\% de la huella urbana actual está afectada por algún tipo de inundación. El aumento de las zonas impermeables en las áreas que discurren a lo largo de la avenida Domingo Diaz ha mantenido un incremento considerable. Para 2003 el área permeable de las áreas que discurren en la Domingo Diaz llegaba a ser 147 Ha y en 17 años se redujeron en un 35.6\%, quedando a ser poco más de $57 \mathrm{Ha}$.

Los desarrollos causan pérdida de masa verde (mayormente tala y quema de árboles), rápidos deslaves y erosión de las superficies no protegidas que causan sedimentación en el lecho de los ríos y los canales de drenaje, y la pérdida de posibles áreas de inundación y retención a lo largo del sistema fluvial. Este incremento en áreas pavimentadas resulta en un excedente de aguas de pluviales que abruma el sistema, el cual no ha sido adaptado para el incremento del deslave (Bajos, 2015).

En un artículo publicado en la revista de Geología de los Estados Unidos en su circular 554 en 1968 ya se venían anunciando investigaciones referentes al impacto de la urbanización avanzada y los problemas que causaría al entorno sino eran tratados sus efectos, citando el artículo, describen: "Hay cuatro efectos interrelacionados pero separables de los 
cambios en el uso de la tierra en la hidrología de un área: cambios en las características del flujo máximo, cambios en la escorrentía total, cambios en la calidad del agua y cambios en las amenidades hidrológicas. Las amenidades hidrológicas son lo que podría llamarse la apariencia o la impresión que el río, su cauce y sus valles, dejan al observador (Leopold, 1968)".

En otro famoso articulo nombrado: "How Urbanization Affects the Water Cycle" traducido sería algo como "Cómo afecta la urbanización al ciclo del agua" se reza que "Las superfícies impermeables asociadas con la urbanización alteran la cantidad natural de agua que toma cada ruta. Las consecuencias de este cambio son una disminución en el volumen de agua que se filtra en el suelo, y un aumento resultante en el volumen y disminución en la calidad del agua superficial" (Partnership, 2007). Y sobre las zonas con un alto grado de urbanización comentan que "En áreas altamente urbanizadas, más de la mitad de toda la lluvia se convierte en escorrentía superficial, y la infiltración profunda es solo una fracción de lo que era naturalmente" (Partnership, 2007). La disminución de flujo que se infiltra y el aumento de agua superficial pasa de $10 \%$ a $55 \%$. A medida que se acorta el tiempo necesario para que se escurra una determinada cantidad de agua, aumenta la tasa máxima de escorrentía (pico de inundación) (Leopold, 1968).

El crecimiento urbano reduce la infiltración, el flujo base y los tiempos de demora y, al mismo tiempo, aumentan drásticamente los volúmenes de flujo de aguas pluviales, la descarga máxima, y la escorrentía superficial (Du, y otros, 2012).

La relación lluvia- escorrentía, de la cual, el aumento de la pendiente, de las áreas provoca una disminución del tiempo de concentración (el cual se define como el tiempo mínimo necesario para que todos los puntos de una cuenca estén aportando agua de escorrentía de forma simultánea al punto de salida) y picos de descarga más altos (SIECA, Manual de Consideraciones Técnicas Hidrológicas e Hidráulicas para la Infraestructura Vial en Centroamérica, 2016). Siguiendo en ese sentido, este estudio busca conocer el incremento de escorrentía superficial, agua superficial que llega a la vía, por el aumento del área permeable en las zonas que discurren sobre la avenida Domingo Diaz como parte del crecimiento urbano. Para esto se utilizo el método SCS, que para análisis de lluvia-escorrentía puede aplicarse para determinar el incremento en la cantidad de escorrentía que se origina por la urbanización (Chow, Maindment, \& Mays, 1994).

SCS (Soil Conservation System) por sus siglas en inglés, calcula el flujo máximo en función del área de la cuenca de drenaje, el almacenamiento potencial de la cuenca y el tiempo de concentración. El procedimiento estudia la relación lluvia-escorrentía, separa la precipitación total en escorrentía directa, retención y extracción inicial para producir la siguiente ecuación para la escorrentía de lluvia (FHWA, 2009).

$$
Q_{D}=\frac{\left(P-0.2 S_{R}\right)^{2}}{P+0.8 S_{R}}
$$

dónde:

$Q D=$ profundidad de escorrentía directa, $\mathrm{mm}$ (pulg);

$P=$ Profundidad de precipitación de 24 horas, $\mathrm{mm}$ (pulg); Esta información está disponible en la mayoría de los manuales de drenaje de las agencias de carreteras al multiplicar la intensidad de lluvia de 24 horas por 24 horas.

$S R=$ Retención, mm (pulg).

Los estudios empíricos encontraron que la $S_{R}$ está relacionada con el tipo de suelo, la cobertura terrestre y la condición de humedad antecedente de la cuenca. Estos están representados por el número de la curva de escorrentía, CN, que se utiliza para estimar SR con la siguiente ecuación (Suelos, 1972).

$$
\mathrm{S}_{\mathrm{R}}=\mathrm{K}_{\mathrm{u}}[(1000 / \mathrm{CN})-10]
$$


dónde:

$C N=$ Número de curva, enumerado en la Tabla 3-6 para diferentes usos de la tierra y tipos de suelo hidrológico. Esta tabla asume condiciones de humedad antecedentes promedio;

$K u=$ Factor de conversión de unidades igual a 25,4 (1,0 en unidades inglesas).

Dentro del Plan Panamá Resiliente promovido por el BID (Banco Interamericano de Desarrollo) a través del Municipio de Panamá se entregó en uno de sus anexos, los estudios hidrológicos realizados dentro del Estudio integral de actuaciones de mitigación de inundaciones en la cuenca del rio Juan Díaz. En este estudio, al cálculo de caudales se le aplico valores de Número de Curva o SCS para la condición de humedad antecedente tipo II y se han considerado que los suelos de toda la cuenca, misma que nuestra área de análisis, son de tipo $\mathrm{C}$ (suelos de lenta infiltración), de acuerdo con su naturaleza edafológica y con las pendientes de la zona media y alta del cauce (CANTABRIA \& BID, Estudio de Factibilidad de actuaciones de Mitigacion de inundaciones en la cuenca baja de Juan Diaz, 2016).

Los datos de lluvia para realizar la estimación lluvia- escorrentía sobre el núcleo de análisis se utilizaron las Curvas IDF presentadas en la investigación de 2015 de Lau y Pérez (Lau \& Perez, 2015), donde se demuestra que las curvas IDF plasmadas para la cuenca del rio Juan Diaz, cuenca del pacifico 144 específicamente, en el Manual de Requisitos para la revisión de Planos de Drenaje Pluvial del MOP, no entrega valores representativos para la condición actual de la cuenca. En efecto, una de las causas de inundación en Panamá es la estimación inapropiada (Lau \& Perez, 2015) de valores de intensidad de lluvia. En la misma investigación de (Lau \& Perez, 2015) en página 168, la gráfica 5.6: Curvas IDF de las cuencas ubicadas en el Pacífico y la curva del MOP para 10 años de periodo de retorno, hasta 3 horas de duración, muestra la diferencia de valores para un periodo de retorno de 10 años entre las gráficas existentes en el manual del MOP y los nuevos valores conseguidos por (Lau \& Perez, 2015). Para nuestro análisis, los valores de lluvia con un periodo de retorno de 10 años se tomarán de las gráficas de (Lau \& Perez, 2015).

Para los Grupos Hidrológicos del Suelo, los valores fueron sacados del Estudio de Factibilidad de Actuaciones de Mitigación de Inundaciones en la cuenca Baja de Juan Diaz, Anexo VII: Estudios Hidrológicos elaborado por IH Cantabria y BID, estos valores son 86 para Áreas Pobladas (2017) y 71 Bosques Secundarios (2017) y 79 para Áreas Pobladas (2003) y 71 Bosques Secundarios (2003). El valor de los Bosques Secundarios mantiene con su valor de 71 por no ser modificada su área en el tiempo.

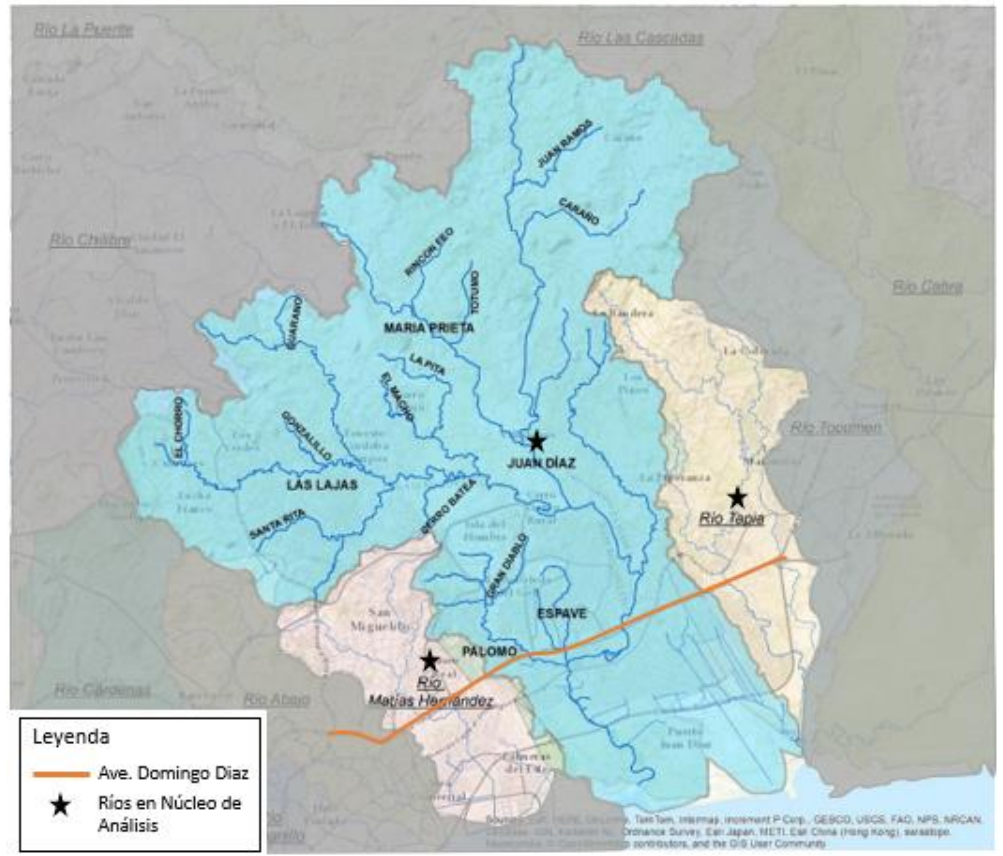

Ilustración 4. Micro cuencas de análisis con zonas con la condición de humedad antecedente tipo II (tipo C: suelos de lenta infiltración). 
Elaboración Propia y (CANTABRIA \& BID, Estudio de Factibilidad de actuaciones de Mitigacion de inundaciones en la cuenca baja de Juan Diaz, 2016).

El impacto sobre la escorrentía superficial por el aumento de las zonas impermeables desde 2003 , ha aumentado en $\mathbf{6 . 8 1 \% . ~}$ Eso significa que en el núcleo de análisis para lluvias con un periodo de retorno de 10 años existe un excedente de $\mathbf{1 1 . 0 9}$ $\mathbf{m m} / \mathbf{h}$ en lluvias de diseño con tiempo de concentración de 10 minutos.

Esto con base en datos meteorológicos y aproximaciones matemáticas sin lograr evaluar datos directos del sitio de estudio, como concluye (Lau \& Perez, 2015) "A pesar de pertenecer a la misma vertiente, las intensidades de eventos extremos generados en las cuencas presentan grandes variaciones entre ellas como para considerarse utilizar una ecuación general por vertiente, ya sea Atlántico o Pacífico. En consecuencia, sería más apropiado aplicar la ecuación de la cuenca correspondiente, sobre todo si la ecuación del MOP subestima la intensidad del sitio de estudio".

Para ampliar el impacto sobre el ciclo hidrológico producido por la urbanización, analizaremos un concepto introducido desde 1958 por Gordon Manley de la Universidad de London quien llamo “islas de calor” a la diferencia de temperatura entre un área urbana y su entorno rural. Una definición más detallada la da (Oke, Johnson, Steyn, \& Watson, 1991) y (Mirzaei, 2015) que definen las islas de calor como el calor de origen antropogénico, la alteración o bloqueo de los patrones de vientos, la alta absorción de radiación solar debido a la implementación de materiales artificiales superficiales que sustituyen la cobertura natural, y en ocasiones con un mayor bloqueo de las emisiones al cielo de onda corta y larga debido al efecto obstructivo de los edificios.

La expansión urbana y sus islas de calor urbanas asociadas también tienen impactos mensurables en los procesos meteorológicos y climáticos, también puede afectar el ciclo global del agua a través del desarrollo de nubes y precipitaciones en las ciudades y sus alrededores (Shepherd \& Burian, 2003).

Algunas ciudades del mundo con estudios de islas de calor muestran de manera ilustrativa el aumento de calor y vientos a favor que generan las zonas más pobladas en una ciudad.

"Las ciudades tienden a ser de uno a 10 grados Fahrenheit [.56 a 5.6 Celsius] más cálidas que los suburbios circundantes y las áreas rurales y el calor adicional puede desestabilizar y cambiar la forma en que el aire circula alrededor de las ciudades", en promedio, las tasas máximas de lluvia en las regiones a favor del viento a menudo excedían los valores máximos en las regiones en contra del viento en un 48\% - 116\% (Daily, 2002). Principalmente durante los meses más cálidos, el calor agregado crea circulaciones de viento y aire ascendente que pueden producir nubes o mejorar las existentes. En las condiciones adecuadas, estas nubes pueden convertirse en productoras de lluvia o tormentas. Se sospecha que el aire convergente debido a las superficies de las ciudades de diferentes alturas, como los edificios, también promueve la elevación del aire necesario para producir nubes y lluvia (Shepherd \& Burian, 2003).

\section{Aumento en el nivel del mar}

El riesgo de eventos naturales como inundaciones podría ser incrementado por el cambio climático. La alteración de ciertos patrones meteorológicos, como, por ejemplo: el potencial aumento del ritmo de subida del nivel del mar en zonas costeras60 de las 77 ciudades más densamente pobladas de América latina están situadas cerca de la costa-, el cambio de patrones locales de precipitación y el potencial incremento de la frecuencia de tormentas, el cambio de la frecuencia y duración de sequias, así como la actividad de ciclones tropicales intensos, podría ser asociada a un clima más caluroso (Brakel, y otros, 2017). Estas alteraciones podrían ser motores de mayores inundaciones con sus correspondientes impactos (Mundial, 2016).

Los retos relacionados con el sistema hídrico de la Ciudad de Panamá incluyen riesgos de inundaciones (precipitación, desbordamiento de ríos y elevación del nivel del mar) (CANTABRIA \& MUPA, Informe de la Misión del Equipo Holandés de Reducción de Riesgo en la cuenca del río Juan Díaz (Resumen-Ejecutivo), 2016). Según el Plan Estratégico de Gobierno (PEG15-19), se estima que el costo anual actual por eventos climáticos recurrentes en el país oscila entre B/.125 y 150 millones/año (0,36\% a 0,42\% del PIB) (Agropecuario, 2018). La data científica ha documentado un incremento en el nivel medio del Mar Caribe, en la entrada Norte del Canal de Panamá. Según las estadísticas, el nivel medio del mar caribe pasó 
de 0,024 pies $(0.73 \mathrm{~cm})$ en 1925 a 0,90 pies $(27 \mathrm{~cm})$ en 2010 (Jimenez, 2018).

En la escala global el aumento del volumen de agua en los océanos debido al calentamiento climático fue más de $15 \mathrm{~cm}$ en últimos cien años. Se predice que el cambio climático causara un aumento del nivel del mar de cerca $30 \mathrm{~cm}$ para el año 2050, que medido para la ciudad de Panama alcanza los $27 \mathrm{~cm}$ en 2010, debido al deshielo de los glaciales y por la expansión térmica de la capa superficial del océano (Kwiecinski \& Cruz, 2008). El incremento del nivel del mar en el pacífico panameño no escapa de esta realidad, en 2008 una investigación del departamento de Biología Marina y Limnología de la Universidad de Panamá estimo el incremento del nivel del mar en la costa del pacífico panameño desde 1909 a 2100. Un estudio de 2016 (Panamá G. d., 2016), concluye que en el último siglo el nivel del mar en el pacífico panameño aumento aproximadamente en $20 \mathrm{~cm}$ y se estima que antes de final de siglo incremente cerca de $55 \mathrm{~cm}$. Históricamente, el aporte de Panamá a las emisiones globales de GEI ha representado el 0,02\%; y las emisiones per cápita de GEI indican que el país no contribuye significativamente al cambio climático. No obstante, Panamá es sumamente vulnerable a sus efectos y ya enfrenta los impactos de este (Panamá G. d., 2016).

\section{Cambio Climático, modificación en los patrones de lluvia sobre el área de análisis}

La precipitación es un eslabón clave en el ciclo global del agua y una comprensión adecuada de su carácter temporal y espacial tendrá amplias implicaciones en el diagnóstico y la predicción del clima, el análisis y la modelización del ciclo global del agua y la energía (GWEC), la previsión meteorológica, la gestión de los recursos de agua dulce y los procesos de la interfaz tierra-atmósfera-océano (Shepherd \& Burian, 2003). Las consecuencias del cambio climático en los sistemas hídricos urbanos incluyen, por una parte, temperaturas más altas, menos precipitaciones y sequías más graves; una mayor frecuencia de las lluvias torrenciales y de los episodios de inundaciones. Precisamente estos extremos hacen que la planificación del espacio urbano y la creación de infraestructura resulten tan complicadas (ONU, Informe Mundial de las Naciones Unidas sobre el desarrollo de los recursos hidricos 2020: agua y cambio climatico. , 2020).

Las precipitaciones en la ciudad y la escorrentilla superficial proveniente de lugares más altos en las cuencas, por lo que drenar adecuadamente en los cuerpos de agua circundantes se vuelve complicado para un sistema rígido de control de aguas superficiales, como lo existente. En el mapa de inundaciones que se muestra en la ilustración 5, donde se agregan

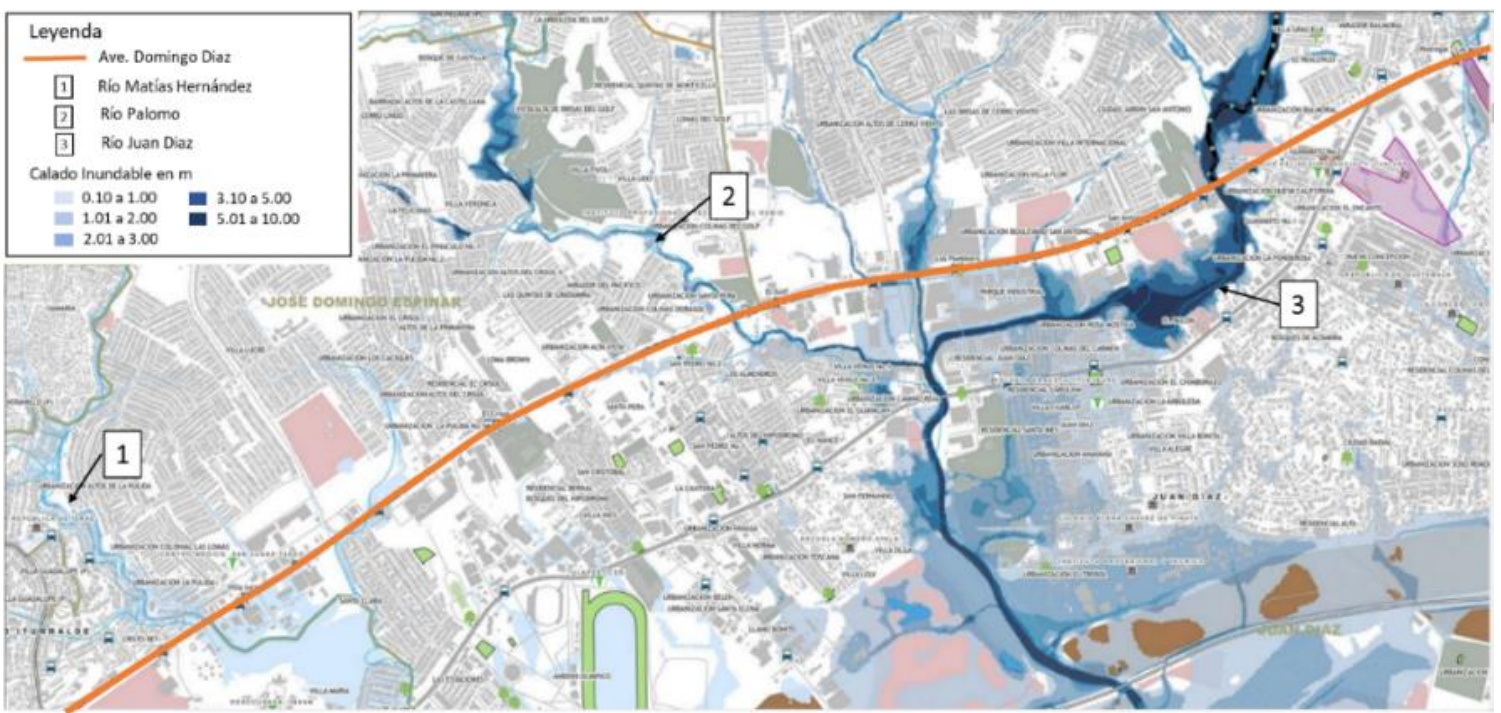

estimaciones por impacto del cambio climático se puede observar el impacto de las precipitaciones para un periodo de retorno de 100 años y los distintos tipos de calado inundable.

Ilustración 5. Zonas inundables en el área de estudio para un periodo de retorno de 100 años. (MUPA, Wetlands, \& Bajos, Diálogos del Agua: Construyendo soluciones sostenibles juntos., 2016) y Elaboración Propia.

Este tipo de fenómenos aquejan las ciudades en medidas avanzas cada año, de ahí la necesidad de adaptar los diseños de 
control de aguas pluviales a estas variaciones o a su prevencion/mitigacion. En el Manual de Consideraciones Tecnicas Hidrologicas e Hidraulicas para la Infraestructura Vial en Centroamérica publicado por el SICEA en 2016, el Ministerio de Obras de Panama aporto a este documento la siguiente informacion sobre consideraciones debidas a variaciones en el patrón de lluvias en los análisis hidrológicos:

- Hasta la fecha de realización de este documento, MOP no incluye en sus Términos de Referencia alguna consideración debida a variaciones en el patrón de lluvias en los análisis hidrológicos (Centroamericana, 2016).

El clima panameño está dictado por su posición, orientación de su estrechez, la influencia de la zona de convergencia intertropical c (ver ilustración 6) y las interacciones océano-atmósfera. El anticiclón semipermanente del Atlántico Norte afecta sensiblemente las condiciones climáticas de nuestro país, ya que desde este sistema se generan los vientos alisios del nordeste que en las capas bajas de la atmósfera llegan a nuestro país, determinando sensiblemente el clima de la República. Existe una zona de confluencia de los vientos alisios de ambos hemisferios (norte y sur) que afecta el clima de los lugares que caen bajo su influencia y que para nuestro país tiene particular importancia: la Zona de Convergencia Intertropical (ZCIT), la cual se mueve siguiendo el movimiento aparente del sol a través del año. Esta migración norte-sur de la ZCIT produce las dos estaciones (seca y lluviosa) características de la mayor parte de nuestro territorio. (ETESA, 2020).

(Fábrega, Nakaegawa, Pinzón, \& Nakayama., 2013) analizaron cuatro regiones, y que cubren, estas cuencas, aproximadamente el $43 \%$ de Panamá. Las cuencas de las regiones de Bocas del Toro y del Canal de Panamá del Canal de Panamá que desembocan en el Océano Atlántico, mientras que las cuencas correspondientes de las regiones de Veraguas y Darién descargan en el Océano Pacífico.

En 2013 se publicó el experimento de (Fábrega, Nakaegawa, Pinzón, \& Nakayama., 2013) quienes a través de MCGA (Atmospheric Global Circulation Models), una explicación más completa sobre los MCGA (Atmospheric Global Circulation Models) de malla de $20 \mathrm{~km}$ vea Mizuta et al. (2006), con malla de $20 \mathrm{~km}$ utilizaron un análisis en el tiempo para el presente y el futuro: para el presente (1979-2002), emplearon valores mensuales de temperatura de la superficie del mar (TSM) y la concentración de hielo marino; para el futuro (2075-2099).

La ilustración 6 muestran las proyecciones hidro climáticas futuras para la precipitación, la evaporación y la escorrentía total en el MCGA de malla de $20 \mathrm{~km}$. La precipitación futura parece aumentar para todas las regiones en al menos un 5\%, con la excepción de algunas zonas de la región de Bocas del Toro. Cabe señalar que incrementos superiores al $15 \%$ se proyectaron para las zonas más pobladas de Panamá. (Fábrega, Nakaegawa, Pinzón, \& Nakayama., 2013).

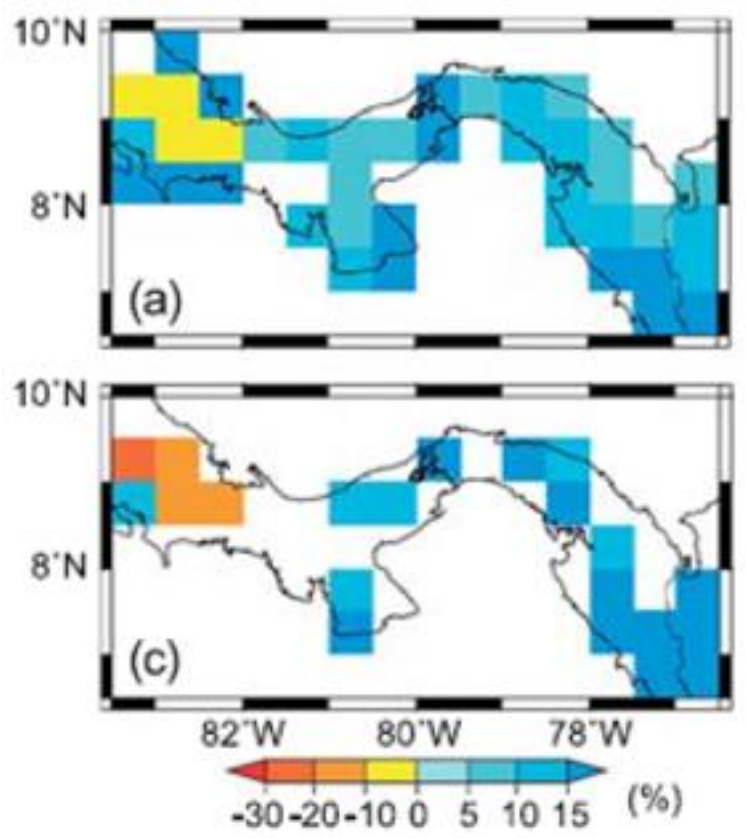

Ilustración 6. (izquierda; a-c) Cambios de la variable hidrológica media anual climatológica en el clima futuro en relación con el actual. (Fábrega, Nakaegawa, Pinzón, \& Nakayama., 2013). 


\section{Estado del sistema de drenaje actual}

Según el Informe "Reducción de Riesgo en la cuenca del Río Juan Díaz" presentado por IH CANTABRIA al Municipio de Panamá la principal causa por el momento, en las áreas que discurren aguas debajo de la cueca del rio Juan Diaz, es probablemente la insuficiente capacidad de los ríos, flujos, alcantarillados y cloacas debido al alto incremento de las corrientes que ocurren en las áreas en constante proceso de urbanización (BID \& CANTABRIA, Estudio Intengral de actuaciones de mitigacion de Inundaciones en la cuenca del rio Juan Diaz, 2016).

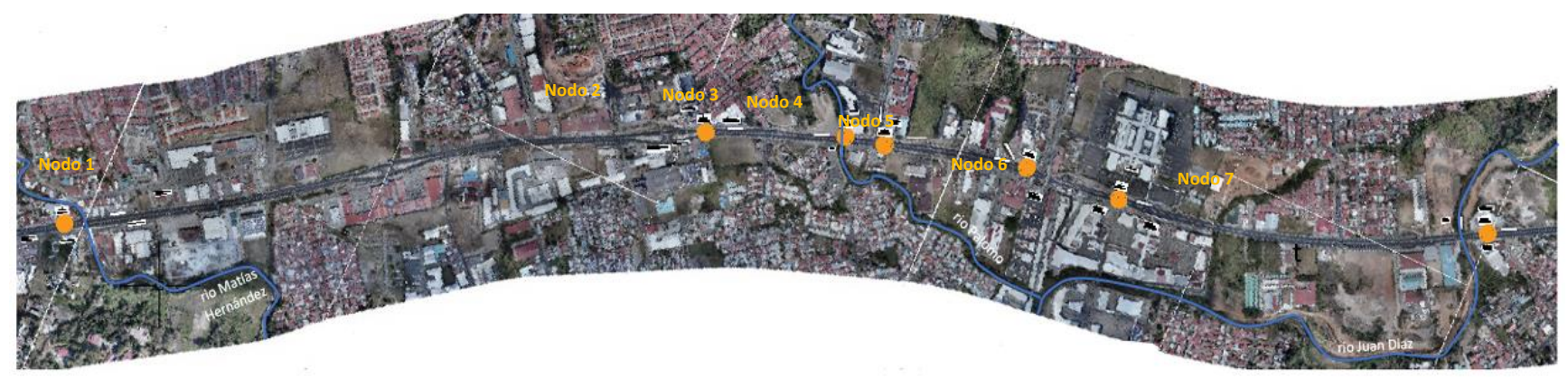

Ilustración 7. Nodos de inundación observados en áreas de análisis. Elaboración propia.

La ilustración 7 muestra los nodos de inundacion encontrados de 2016 en el área de análisis y evaluados hasta 2019. La ubicación de los nodos es la siguiente:

Nodo 1. Se ubica diagonal a la Cárcel de Mujeres antes del cruce del rio Matías Hernández.

Nodo 2. Se ubica diagonal a Ricardo Pérez sobre la Domingo Diaz justo antes del acceso a P.H. Mystics Hills. Nodo 3 y 4. Nodo 3 se ubica justo encima del cruce del rio Palomo y el Nodo 4 se ubica debajo del puente vehicular de la avenida Manuel Zarate.

Nodo 5 y 6. Nodo 5 se ubica justo después del cruce del afluente del rio Espave y antes del Patio de Buses de Mi Bus en los Pueblos y el Nodo 6 se ubica diagonal a Farmacias Arrocha de los Pueblos y justo en frente a la parte frontal de Metromall.

Nodo 7. Se ubica pasado el cruce del rio Juan Diaz con la avenida Domingo Diaz y justo en frente a la Universidad Americana.

La observación de los nodos permitió conocer las zonas afectadas por inundaciones y conocer si existía una relación de recurrencia entre estos años. Todo el análisis de las revisiones, para cada nodo, en los años 2016 y 2019 , a través de registros fotográficos están resumidas en la tabla 1.

Iniciando en el año 2016 luego de la culminación de las obras de Ampliación a cuatro carriles de la avenida Domingo Diaz realizadas por el Consorcio ICA-MECO por un monto de 273 millones de dólares (Almanza, 2014) hasta el año 2019 posterior a la culminación del nuevo sistema de drenaje pluvial de la avenida Domingo Diaz por la construcción de la Línea 2 del Metro de Panamá bajo un costo de 1,875 billones de dólares (Telemetro, 2019). 
Tabla 1. Tabla Resumen: obra civil y recurrencia de inundación en los años 2016 y 2019. Nodo Estado en 2016 Obras Civiles Estado en 2019 Obras Civiles Recurrencia

\begin{tabular}{|c|c|c|c|c|c|}
\hline 1 & Inundado & $\begin{array}{c}\text { Ampliación de } \\
\text { la Domingo } \\
\text { Diaz }\end{array}$ & Inundado & $\begin{array}{c}\text { Linea } 2 \text { del } \\
\text { Metro de } \\
\text { Panamá }\end{array}$ & $\mathrm{Si}$ \\
\hline 2 & Inundado & $\begin{array}{c}\text { Ampliación de } \\
\text { la Domingo } \\
\text { Diaz }\end{array}$ & Inundado & $\begin{array}{l}\text { Línea } 2 \text { del } \\
\text { Metro de } \\
\text { Panamá }\end{array}$ & Si \\
\hline 3 & Inundado & $\begin{array}{c}\text { Ampliación de } \\
\text { la Domingo } \\
\text { Diaz }\end{array}$ & Inundado & $\begin{array}{l}\text { Línea } 2 \text { del } \\
\text { Metro de } \\
\text { Panamá }\end{array}$ & $\mathrm{S}_{i}$ \\
\hline 4 & Inundado & $\begin{array}{c}\text { Ampliación de } \\
\text { la Domingo } \\
\text { Diaz }\end{array}$ & Inundado & $\begin{array}{l}\text { Línea } 2 \text { del } \\
\text { Metro de } \\
\text { Panamá }\end{array}$ & Si \\
\hline 5 & Inundado & $\begin{array}{c}\text { Ampliación de } \\
\text { la Domingo } \\
\text { Diaz }\end{array}$ & Inundado & $\begin{array}{l}\text { Linea } 2 \text { del } \\
\text { Metro de } \\
\text { Panamá }\end{array}$ & $\mathrm{S}_{i}$ \\
\hline 6 & Inundado & $\begin{array}{l}\text { Ampliación de } \\
\text { la Domingo } \\
\text { Diaz }\end{array}$ & Inundado & $\begin{array}{l}\text { Línea } 2 \text { del } \\
\text { Metro de } \\
\text { Panamá }\end{array}$ & $\mathrm{S}_{i}$ \\
\hline 7 & Inundado & $\begin{array}{c}\text { Ampliación de } \\
\text { la Domingo } \\
\text { Diaz }\end{array}$ & Inundado & $\begin{array}{l}\text { Línea } 2 \text { del } \\
\text { Metro de } \\
\text { Panamá }\end{array}$ & $\mathrm{S}_{1}$ \\
\hline
\end{tabular}

Como se muestra en las tablas 1 y 2, cada nodo cuenta con problemas de inundación recurrentes desde 2016, cada nodo sostuvo sus réplicas de inundación en 2019 luego de adecuaciones a la mediana y modificaciones a gran parte de los accesos sobre la avenida con la construcción de la Línea 2 del Metro de Panamá. 
Tabla 2. Tabla Resumen: recurrencia de inundación en los años 2016 y 2019.

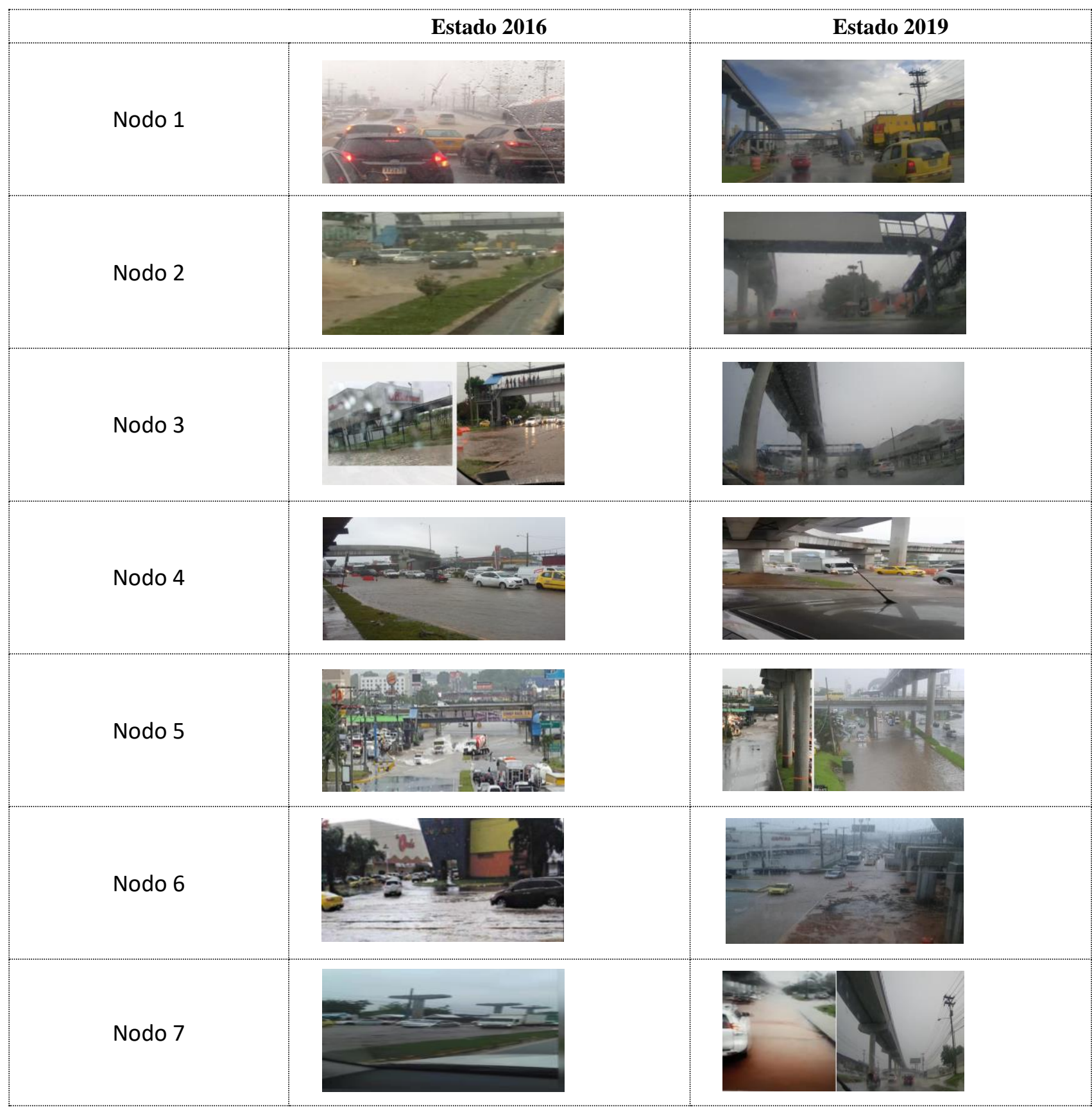

Esta investigación ha mostrado lo ineficiente que han sido las soluciones grises (obras civiles exclusivamente de construcción, rígidas y con límites de diseño: cunetas longitudinales, tragantes, parrillas, tubos de descarga y cordones cunetas) para mantener un mínimo de funcionalidad ante los cambios y modificaciones climáticas. Por ejemplo, los tragantes construidos en 2016 contaban con una abertura de acceso para la lámina de agua de $10 \mathrm{~cm}$ y en 2019 cuentan con una abertura de acceso de $35 \mathrm{~cm}$, un aumento del $350 \%$ en la abertura para controlar el aumento de escorrentía y su 
velocidad de acceso, función que no se cumple aun en 2019. Los tragantes con aberturas de $35 \mathrm{~cm}$ siguen sin tener la capacidad de absorber la lluvia en época lluviosa ni con la llegada de lluvias extraordinarias propias de modificaciones climáticas inducidas o naturales, debido a que un sistema rígido sin capacidad de adaptación.

En cada uno de los años estudiados, el sistema de drenaje pluvial se encontraba aprobado por el Ministerio de Obras Públicas y con dichas obras entregadas por el contratista a totalidad.

Como se demostró a través de las ilustraciones, las nuevas estructuras de drenaje de 2019 solo impactaron la mediana de la Domingo Diaz, los bordes de la vía, en los núcleos de inundacion, aún mantienen el mismo sistema de drenaje pluvial desde 2016.

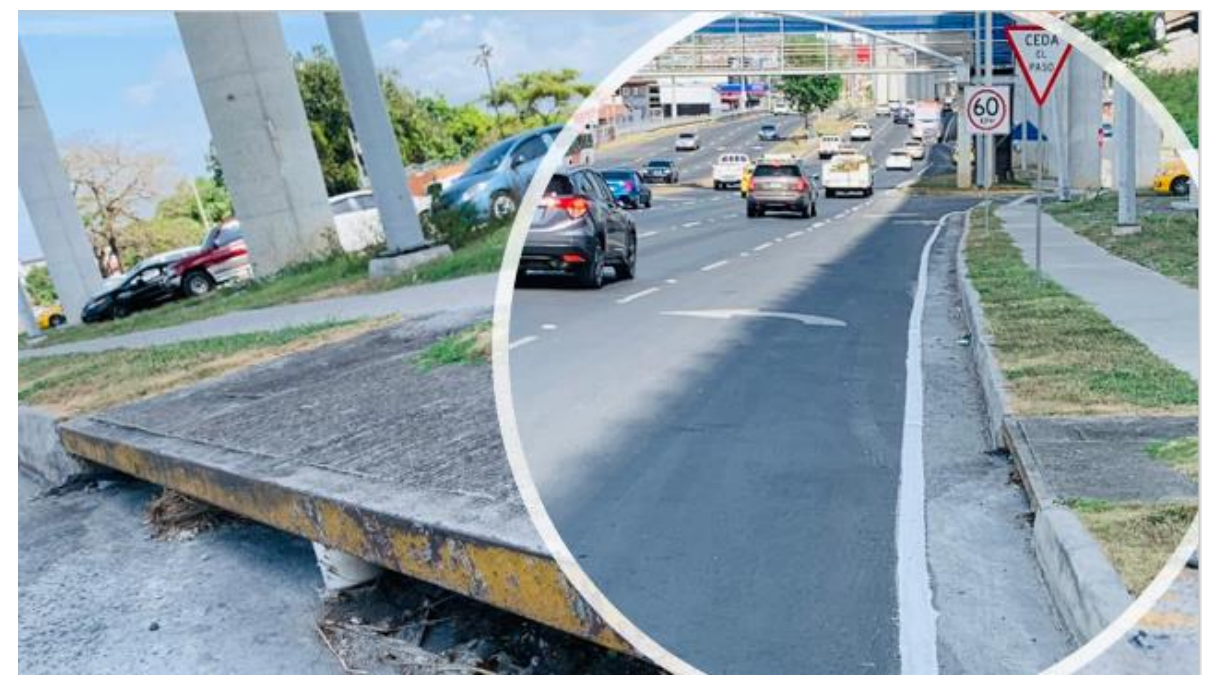

Ilustración 8. Altura de estructura de drenaje construido en 2016 sobre la Domingo Diaz.

A pesar de la construcción de obras de ingeniería, grandes y costosas, las soluciones para el sistema de drenaje pluvial sigue siendo la misma de hace varias décadas, obras grises rígidas cada vez mas grandes focalizadas sin la evaluación integral del sistemas ausentando y manteniendo en el olvido factores de incidencia como el aumento del nivel del mar, el cambio climático, el crecimiento urbano que propicia modificaciones en el espectro climático y el aumento de aguas superficiales que llegan desde áreas permeables al borde la avenida Domingo Diaz.

Todo lo descrito en el párrafo anterior, se puede visualizar, en un rápido recorrido mental (imaginando la actualidad del resto de la ciudad), a lo largo de toda la ciudad de Panama.

\section{Conclusiones}

- En los últimos 12 años, de 2008 a 2020, la ciudad de Panamá sufrió daños económicos por poco más de 164 millones de dólares y un aumento de asentamientos vulnerables. Según (Panamá C. N., 2015) en los últimos 5 años, el Estado Panameño ha invertido cerca de US\$331.03 millones en reconstrucciones de asentamientos por eventos climatológicos extremos y a pesar de esto y que sobran fundamentos descritos en esta investigación, el Manual de Requisitos para la Revisión de Planos donde se dictan las normas para la construcción de drenajes pluviales, no ha sido modificado/adaptado/actualizado desde hace ya 18 años.

- Desde 2002 la huella urbana aguas arriba de las cuencas ha experimentado un crecimiento continuo, contando en 2002 con 1,883 hectáreas hasta hoy en 2020 contar con 1,237 hectáreas con una pérdida del 35,6\% de la cobertura vegetal. 
- El impacto sobre la escorrentía superficial por el aumento de las zonas impermeables desde 2003 ha aumentado en $6.81 \%$ eso significa que, en el núcleo de análisis, para lluvias con un periodo de retorno de 10 años existe un excedente de $11.09 \mathrm{~mm} / \mathrm{h}$ en lluvias de diseño con tiempo de concentración de 10 minutos.

- Los tragantes con aberturas de $35 \mathrm{~cm}$, incrementados en $350 \%$ desde 2016, siguen sin tener la capacidad de absorber la lluvia, en los núcleos de inundacion, en época lluviosa ni con la llegada de lluvias extraordinarias propias de modificaciones climáticas inducidas o naturales, debido a que es un sistema rígido sin capacidad de adaptación.

- El estudio confirmó, en la comparación de los años 2017 y 2019, que los sistemas de drenaje pluvial existentes se encontraban en general en buenas condiciones estructurales y su desempeño fue el esperado de acuerdo con su diseño. Y que en ambos años de evaluación sufrió colapsos por la precipitación de la estación lluviosa dentro del áreas de análisis.

\section{Referencias}

500, P. (2017). Panamá Cosmopolita: La exposición de 1916 y su legado. Panamá: Phoniex Editors .

Administration, F. F. (2009). Urban Drainage Desing Manual. Washington : FHWA Federal Highway Administration.

Agropecuario, M. d. (Junio de 2018). Ministerio de Desarrollo Agropecuario MIDA . Obtenido de www.mida.gob.pa: https://www.mida.gob.pa/direcciones/direcciones_nacionales/unidad-ambiental/resumen-del-plan-nacional-decambio-clim-tico.html

Almanza, C. (14 de Enero de 2014). Ampliacion de la Domingo Diaz culminara en mayo . La Prensa , pág. 12.

Bajos, R. d. (2015). Infoem de la mision del Equipo Holandes de Reduccion de Riesgos. Panamá : Reino de los Paises Bajos .

BBVA, B. (2017). Urbanizacion en America Latina . Madrid, España : BBVA Research .

BID. (2015). Plan Acción Panamá Metropolitana: Sostenible, Humana y Global. Panamá: Banco Interamericano de Desarrollo (BID).

BID, \& CANTABRIA, I. (2016). Estudio Intengral de actuaciones de mitigacion de Inundaciones en la cuenca del rio Juan Diaz. Panamá : Banco Interamericano de Desarrollo .

Brakel, L., Keyzer, L., Hasper, Y., Legene, M., Willemse, J., \& Stap, E. v. (2017). Reducing flood risk in Cartagena de Indias . Cartagena de Indias, Colombia : TU Delft University .

CANTABRIA, I., \& BID. (2016). Estudio de Factibilidad de actuaciones de Mitigacion de inundaciones en la cuenca baja de Juan Diaz. Panamá : Banco Interamericano de Desarrollo .

CANTABRIA, I., \& MUPA. (2016). Informe de la Misión del Equipo Holandés de Reducción de Riesgo en la cuenca del río Juan Díaz (Resumen-Ejecutivo). Panamá : Municipio de Panamá .

Chong, E. (1998). Carreteras Construidas en Panama de 1920 a 1970 (Tesis de Licenciatura). Panamá : Universidad Santa Maria la Antigua .

Chow, V. T., Maindment, D. T., \& Mays, L. (1994). Hidrologia Aplicada. Santa Fe de Bogota, Colombia: McGraw Hill Interamericana S.A.

Daily, S. (19 de Junio de 2002). El satélite de la NASA confirma que las islas de calor urbanoaumentan las precipitaciones alrededor de las ciudades. Obtenido de www.sciencedaily.com/releases/2002/06/020619074019.htm

Desastres, D. S. (22 de Enero de 2019). Sistema de Inventario de Desastres. Obtenido de desinventar.org : https://www.desinventar.net/DesInventar/profiletab.jsp

Du, J., Qian, L., Rui, H., Zuo, T., Zheng, D., Xu, Y., \& Xu, C. (2012). Urbanization on Annual runoff and Flood Events Using an Integrated Hydrological Modeling System for Qinhuai River Basin, China. Journal of Hydrology, 464 -465 .

FHWA. (2009). Urban Drainage Desing Manual: Third Edicion. Washington, USA: Federal Highway Administration FHWA.

Gordon, C. A. (24 de Octubre de 2019). La Estrella de Panamá . Obtenido de laestrella: https://www.laestrella.com.pa/nacional/191025/urbana-panama-fallido-sintesis

Jimenez, M. (20 de Mayo de 2018). La Estrella de Panamá . Obtenido de www.laestrella.com.pa: 
http://laestrella.com.pa/vida-de-hoy/planeta/canal-panama-frente-reto-cambio-climatico/24063992

Kwiecinski, B., \& Cruz, L. d. (2008). El cambio climatico y su proyeccion sobre el nivel del mar en la costa de pacifico de panamá. . Tecnociencia UP, Volumen $10, \mathrm{~N}^{\circ} 2$.

Lau, A., \& Perez, A. (2015). Generación de Relaciones Intensidad Duración Frecuencia para Cuencas en la republica de Panamá (Tesis de Lincenciatura). Panamá: Univerisdad Tecnologica de Panamá.

Leopold, L. B. (1968). Hidrologia para la planificacion urbana: una guia sobre los efectros hidrologicos del urso del suelo urbano. Washington, USA: United State Departament of Interior .

Mirzaei, P. A. (2015). Recent challenges in modeling of urban heat island. Sustainable Cities and Society, 200-206.

Mundial, B. (2016). Ocurrencia y gestión de inundaciones en América Latina y el Caribe factores claves y experiencia adquirida . Washington, USA : Banco Mundial .

MUPA. (2018). Plan Estrategico Distrital . Panamá : MUPA .

MUPA. (2018). Plan Estratégico Distrital, Políticas Locales y Plan de Ordenamiento Territorial del Distrito de Panamá . Panamá: Municipio de Panamá.

MUPA, B. (2017). Estudios base para la ciudad de Panamá: estudio de crecimiento urbano . Panamá : Banco Internamericano de Desarrollo .

MUPA, Wetlands, \& Bajos, R. d. (2016). Diálogos del Agua: Construyendo soluciones sostenibles juntos. Panamá: Reino de los Paises Bajos .

Officials, A. A. (2011). Geometric Desing of Highways and Streets . Washington: AASHTO.

Oke, T. R., Johnson, G. T., Steyn, D. G., \& Watson, I. D. (1991). Simulation of surface urban heat islands under 'ideal' conditions at night—part 2 Diagnosis of causation. Boundary-Layer Meteorology. Boundary-Layer Meteorology, 339-358.

ONU. (2019). Perspectivas de la poblacion mundial 2019: Aspectos destacados. . Nueva York, USA: Naciones Unidas .

ONU. (2020). Informe Mundial de las Naciones Unidas sobre el desarrollo de los recursos hidricos 2020: agua y cambio climatico. . Washington, USA: Organizacion de las Naciones Unidas ONU.

Panamá, C. N. (2015). Plan Nacional de Seguridad Hídrica 2015-2050: Agua para Todos. . Panamá, República de Panamá.: Comité de Alto Nivel de Seguridad Hídrica 2016. .

Panamá, G. d. (2016). Contribución Nacionalmente Determinada a la Mitigación del Cambio Climático (NDC) de la Republica Panamá ante la Convención Marco de Naciones Unidas sobre Cambio Climático (CMNUCC). Panamá : Gobierno de la Replubica de Panamá .

Panamá, M. d., \& BID. (2016). Diagnóstico y Análisis del Área de Influencia de la Linea 2 del Sistema de Metro de Panamá. Panamá: Metro de Panamá.

Partnership, C. W. (2007). Como afecta la urbanizacion al ciclo del agua . California, USA : The University of Connecticut.

PIARC. (2015). Marco Internacional para la adaptación de las infraestructuras de carreteras frente al cambio climático. . Francia : Asociacion Mundial de la Carretera .

Pyke, C., P, M., Thomas, W., James, J., \& Jeremy, L. J. (2011). Pyke, C., Warren, M. P, Johnson, T., LaGro, J., Scharfenberg, J., Groth, P., Freed, R., Schroeer, W. y Main, E. (2011). Evaluación del desarrollo de bajo impacto para la gestión de aguas pluviales con precipitación cambiante debido al cambio climático. Pa. USDA Paisajismo y Urbanismo, 166-173.

Reglamentan las urbanizaciones en la Republica de Panamá, Ley 78 (23 de Junio de 1941).

Resolucion N ${ }^{\circ}$ 008-03 (Ministerio de Obras Públicas 11 de Marzo de 2003).

Rockefeller, 1. C. (2017). Panamá Resiliente . Panamá: Rockefeller Fundation.

Shamseldin, A. (2019). Eficiencia del desarrollo de bajo impacto (LID) para mitigar los impactos de la urbanización y el cambio climático en Ammán, Jordania. Actas del $38^{\circ}$ Congreso Mundial de la IAHR (Panamá). Panamá : IAHR

Shepherd, J. M., \& Burian, S. J. (2003). Detección de anomalías en las precipitaciones inducidas por zonas urbanas en una ciudad costera importante. Interacciones con la Tierra AMS American Meteorology Society , 1-17.

SIECA. (2011). Manual Centroamericano de Normas para el Diseño Geometrico de Carreteras . España: SIECA.

SIECA. (2016). Manual de Consideraciones Técnicas Hidrológicas e Hidráulicas para la Infraestructura Vial en Centroamérica. El Salvador : Agencia de Cooperacion Internacion de Japon JICA.

Street, S. (2017). Aforo Vehicular de análisis para la Linea 2 del Metro de Panamá . Panamá : Smart Street .

Suelos, S. d. (1972). Manual Nacional de Ingeniería, Sección 4: Hidrología. Washington, USA: Servicio de Conservación de Suelos (SCS).

Tello, H. (1977). Drenaje de Carreteras (Tesis de Licenciatura). Panamá: Universidad Santa Maria la Antigua USMA.

Tucci, C. E. (2007). Gestion de Inundaciones Urbanas . Porto Alegre, Brazil : OMM Organizacion Meteorologica Mundial 
UNESCO. (2011). Proyecto SAT . San Jose, Costa Rica : Organización de las Naciones Unidas para la Educación, la Ciencia y la Cultura.

Uribe, Á. (22 de Junio de 2018). Memoria de la Ciudad III. Obtenido de Memoria de la Ciudad III: https://www.youtube.com/watch?v=KD85E7sVyMw\&t=857s

Uribe, A. (19 de Febrero de 2020). Diplomado Ciudad Sustentable Microclima y Movilidad - SUSCity. (I. Trejos, Entrevistador) 